\title{
Estimativa da assimilação potencial de carbono em dosséis de espécies de braquiária
}

\author{
Márcio André Stefanelli Lara(1) e Carlos Guilherme Silveira Pedreira(2)
}

\begin{abstract}
(1)Universidade Federal de Lavras, Departamento de Zootecnia, Caixa postal 3037, CEP 37200-000, Lavras, MG. E-mail: marcioaslara@gmail.com (2)Universidade de São Paulo, Escola Superior de Agricultura Luiz de Queiroz, Departamento de Zootecnia, Avenida Pádua Dias, № 11, CEP 13418-970 Piracicaba, SP. E-mail: cgspedreira@usp.br
\end{abstract}

Resumo - O objetivo deste trabalho foi quantificar a fotossíntese foliar, durante o período de rebrotação, e estimar a fotossíntese de dosséis de duas espécies e cinco cultivares de braquiária, com base na arquitetura foliar e no ambiente luminoso no verão e inverno. Foram avaliadas quatro cultivares de Urochloa brizantha (Marandu, Xaraés, Arapoty e Capiporã) e uma de U. decumbens (Basilisk). Utilizou-se o delineamento de blocos ao acaso, com quatro repetições. As parcelas foram irrigadas e adubadas com $220 \mathrm{~kg} \mathrm{ha}^{-1}$ por ano de $\mathrm{N}$ e $\mathrm{K}_{2} \mathrm{O}$. Foi avaliada a taxa de assimilação de carbono nas folhas no dossel, o índice de área foliar (IAF) e a interceptação luminosa (IL). A fotossíntese foliar não variou entre cultivares ou estações, e houve assimilação de $0,91 \mathrm{mg} \mathrm{m}^{-2} \mathrm{~s}^{-1}$ de $\mathrm{CO}_{2}$. Na fase inicial de rebrotação, o potencial fotossintético dos dosséis de verão e inverno foi baixo $\left(0,80 \mathrm{mg} \mathrm{m}^{-2} \mathrm{~s}^{-1}\right.$ de $\left.\mathrm{CO}_{2}\right)$; entretanto, dosséis forrageiros no inverno apresentaram maior aumento da assimilação de carbono por unidade de IAF. A fotossíntese de dossel, no final do período de rebrotação, foi 15\% menor no inverno em comparação ao verão, e as correlações entre fotossíntese foliar e de dossel com a produção de forragem foram baixas. O IAF influencia fortemente os resultados do modelo de simulação da fotossíntese de dossel de espécies de braquiária.

Termos para indexação: Brachiaria, Urochloa, fotossíntese de dossel, fotossíntese foliar, índice de área foliar, modelagem.

\section{Potential carbon assimilation estimate in canopies of Brachiaria species}

Abstract - The objective of this work was to quantify the leaf photosynthesis during forage regrowth and to estimate the canopy photosynthesis of two species and five Cultivars of brachiaria, based on leaf architecture and light environment in the summer and winter. Four cultivars of Urochloa brizantha (Marandu, Xaraés, Arapoty e Capiporã) and one of $U$. decumbens (Basilisk) were evaluated. It was used a randomized complete block design with four replicates. The plots were irrigated and fertilized with $220 \mathrm{~kg} \mathrm{ha}^{-1}$ per year of $\mathrm{N}$ and $\mathrm{K}_{2} \mathrm{O}$. Carbon assimilation in leaves and canopies, leaf area index (LAI) and light interception (LI) were evaluated. Leaf photosynthesis did not vary among cultivars or seasons, and there was assimilation of $0.91 \mathrm{mg} \mathrm{m}^{-2} \mathrm{~s}^{-1} \mathrm{CO}_{2}$. In early regrowth, the canopy photosynthetic potential in the summer and winter was low $\left(0.80 \mathrm{mg} \mathrm{m}^{-2} \mathrm{~s}^{-1} \mathrm{CO}_{2}\right)$; however, winter canopies showed greater increase in carbon assimilation per unit increase of LAI. Canopy photosynthesis at the regrowth end was $15 \%$ lower in the winter, in comparison to the summer, and the correlations of both leaf and canopy photosynthesis with forage production were low. The leaf area index has a strong impact on the simulation model results of canopy photosynthesis of brachiaria.

Index terms: Brachiaria, Urochloa, canopy photosynthesis, leaf photosynthesis, leaf area index, modeling.

\section{Introdução}

$\mathrm{Na}$ atividade pecuária, a utilização adequada das plantas forrageiras já estabelecidas e a introdução de genótipos mais produtivos são passos importantes no melhoramento dos índices zootécnicos da fazenda. Além disso, em plantas forrageiras, o acúmulo de matéria seca (MS) é resultante de interações complexas entre atributos genéticos e ambiente e de seus efeitos sobre os processos fisiológicos e as características morfológicas das plantas.

Segundo Loomis \& Williams (1969), a arquitetura do dossel interfere tanto na distribuição da luz dentro da população de plantas como na circulação de ar, e ainda afeta os processos de transferência de $\mathrm{CO}_{2}$ e evapotranspiração. Portanto, a arquitetura do dossel vegetativo é determinante dos padrões de interceptação luminosa pelas plantas e, provavelmente, uma das características mais importantes que determina sua habilidade de crescimento.

Rymph et al. (2004) afirmou que, numa comunidade de plantas, a eficiência na conversão da energia luminosa em fitomassa depende das taxas de fotossíntese de folhas individuais. A capacidade fotossintética de folhas individuais apresenta grande variação, que pode 
ser causada por fatores como quantidade e qualidade da radiação incidente - determinados pela elevação solar, nebulosidade, e temperatura ambiente e da própria folha -, suprimento de água e, principalmente, pelo estádio de desenvolvimento da folha (Pedreira et al., 2001; Braga et al., 2006, 2008). Portanto, as taxas de fotossíntese foliar não representam as taxas de fotossíntese do dossel e, quando medidas em curtos períodos de tempo, dificilmente explicam variações em produção, pois não expressam a assimilação total de $\mathrm{CO}_{2}$ pela comunidade de plantas ao longo de um dia ou de uma estação (Zelitch, 1982).

As respostas agronômicas de espécies forrageiras ao manejo e ao ambiente podem ser preditas de forma a melhorar as estratégias de manejo de colheita de forragem, seja por corte ou por pastejo (Rymph et al., 2004). O uso de modelos matemáticos é uma alternativa para a estimativa da fotossíntese de comunidades vegetais, pois são muitos os fatores que a influenciam, o que torna difícil conhecer seus detalhes apenas por meios experimentais. Nesse contexto, a modelagem matemática de processos produtivos vem tomando espaço na pesquisa agropecuária. Um dos modelos que estima a fotossíntese do dossel e sua resposta à radiação é proposto por Boote \& Jones (1987) e integra algumas das variáveis determinantes da assimilação de carbono pelas plantas, tais como índice de área foliar (IAF), coeficiente de extinção luminosa, densidade de fluxo da radiação e taxa máxima de fotossíntese foliar.

Aspectos relacionados à estrutura e à arquitetura das plantas são fundamentais em modelos de crescimento de culturas agrícolas e ecossistemas (Thornley, 2002). É importante conhecer os padrões morfofisiológicos das plantas e padrões estruturais do dossel, para o entendimento da dinâmica de produção de forragem, o que otimiza o desempenho de plantas em qualquer sistema de produção com base no uso de pastagens.

O objetivo deste trabalho foi quantificar a fotossíntese foliar, o IAF e a interceptação luminosa (IL), durante o período de duas rebrotações de cinco cultivares de Urochloa spp. (Syn. Brachiaria), uma no verão e outra no inverno, e modelar a fotossíntese de dosséis vegetativos sob desfolhação intermitente por corte.

\section{Material e Métodos}

$\mathrm{O}$ experimento foi realizado em área experimental do Departamento de Zootecnia, da Escola Superior de Agricultura Luiz de Queiroz, da Universidade de São Paulo, em Piracicaba, SP, a $22^{\circ} 42^{\prime}$ S e $47^{\circ} 30^{\prime} \mathrm{W}$, a $580 \mathrm{~m}$ de altitude, com média anual de precipitação de $1.002 \mathrm{~mm}$ e temperatura média de $23,6^{\circ} \mathrm{C}$, durante o verão agrostológico (outubro a março), e de $13,3^{\circ} \mathrm{C}$ durante o inverno agrostológico (abril a setembro). $\mathrm{O}$ solo da área experimental foi classificado como Nitossolo Vermelho eutroférrico típico (Santos et al., 2006). Suas características químicas, avaliadas na camada de 0-20 cm em outubro de 2007, foram: $\mathrm{pH}$, 5,2; MO, $30 \mathrm{~g} \mathrm{dm}^{-3} ; \mathrm{P}, 17 \mathrm{mg} \mathrm{dm}^{-3} ; \mathrm{K}, 3,9 \mathrm{mmol}_{\mathrm{c}} \mathrm{dm}^{-3}$; $\mathrm{Ca}, 54 \mathrm{mmol}_{\mathrm{c}} \mathrm{dm}^{-3}$; $\mathrm{Mg}, 19 \mathrm{mmol}_{\mathrm{c}} \mathrm{dm}^{-3} ; \mathrm{H}+\mathrm{Al}$, $31 \mathrm{mmol}_{\mathrm{c}} \mathrm{dm}^{-3} ; \mathrm{SB}, 66 \mathrm{mmol}_{\mathrm{c}} \mathrm{dm}^{-3} ; \mathrm{T}, 96,9 \mathrm{mmol}_{\mathrm{c}} \mathrm{dm}^{-3}$; $\mathrm{V}(\%), 68$.

Foram feitas adubações de produção, no total de $120 \mathrm{~kg} \mathrm{ha}^{-1} \mathrm{de} \mathrm{Ne} \mathrm{K} 2 \mathrm{O}$ por ano, nas formas de $\left(\mathrm{NH}_{4}\right)_{2} \mathrm{SO}_{4}$ e $\mathrm{KCl}$, respectivamente. Para tanto, foram realizadas, após cada corte, adubações manuais com $20 \mathrm{~kg} \mathrm{ha}^{-1} \mathrm{de}$ $\mathrm{Ne} \mathrm{K}_{2} \mathrm{O}$, durante os 11 ciclos de rebrotação. Durante os 370 dias do experimento (12 de outubro de 2007 a 17 de outubro de 2008), as plantas sempre foram cortadas a $15 \mathrm{~cm}$ do nível do solo. O manejo da irrigação foi baseado no monitoramento das condições hídricas do solo, por meio de três tensiômetros instalados nas parcelas, a $25 \mathrm{~cm}$ de profundidade. A irrigação era realizada sempre que os tensiômetros registravam valores de potencial hídrico no solo entre $-0,3$ e - $0,4 \mathrm{kPa}$ e, também, após cada adubação, para maximizar a eficiência de absorção do adubo aplicado.

Os tratamentos corresponderam a quatro cultivares de Urochloa brizantha (Marandu, Xaraés, Arapoty e Capiporã) e uma de Urochloa decumbens (Basilisk), colhidas a cada 28 dias no verão e 42 dias no inverno, o que teria simulado um sistema de lotação intermitente. Utilizou-se o delineamento experimental de blocos completos ao acaso, com quatro repetições. A área foi dividida em 20 unidades experimentais (parcelas) de $36 \mathrm{~m}^{2}$ cada uma.

As medições de IL e IAF foram feitas durante duas rebrotações, uma no verão (8/12/2007 a 9/1/2008) e outra no inverno (24/7/2008 a 4/9/2008), tendo-se iniciado imediatamente após o corte, e a cada sete dias no verão e dez dias no inverno, para que se pudessem caracterizar as variações estruturais da comunidade vegetal e levantar os dados necessários para alimentar o modelo de fotossíntese de dossel. Para as avaliações de IL e IAF, foi utilizado o analisador de dossel LI-COR modelo LAI 2000 (LI-COR, Lincoln, NE, EUA), que 
permite amostragens rápidas e não destrutivas, e cujo funcionamento foi descrito por Welles \& Norman, (1991). Foram tomados dez pontos representativos da condição média do dossel, em cada parcela, nas ocasiões de amostragem, à proporção de uma medida acima para cinco medidas abaixo do dossel, em duas repetições, sempre em estações posicionadas entre touceiras.

A fotossíntese líquida de folhas individuais foi medida nos mesmos ciclos de verão e inverno, assim como as leituras de IL e IAF. Para a obtenção desses dados, foi usado um sistema portátil medidor de fotossíntese, modelo LI-6400 (LI-COR, Lincoln, NE, EUA). Foram medidas as taxas de fotossíntese de quatro folhas mais jovens completamente expandidas, em cada parcela, no total de 16 folhas por genótipo, por dia de avaliação. Optou-se por um critério de avaliação visual, de modo a selecionar as melhores folhas presentes, com um mínimo de limbo intacto, verdes e limpas.

As leituras foram realizadas entre 8 e $11 \mathrm{~h}$ da manhã, período em que as plantas apresentam seu máximo potencial fotossintético. As folhas utilizadas eram provenientes de perfilhos, escolhidos em touceiras de plantas diferentes, que representavam a média do dossel na unidade experimental. A intensidade de luz usada dentro da câmara foi de $2.000 \mu \mathrm{mol} \mathrm{m}^{-2} \mathrm{~s}^{-1}$ de fótons, e a concentração de $\mathrm{CO}_{2}$ foi de $350 \mu \mathrm{mol}$ por mol de ar, como referência na programação do aparelho, cuja fonte vinha de cilindros de $\mathrm{CO}_{2}$ do kit LI-COR. Médias de fotossíntese foliar foram calculadas para cada parcela.

As medições de fotossíntese foliar, realizadas no início dos ciclos de acompanhamento, nem sempre foram realizadas nas folhas mais jovens completamente expandidas, em razão da altura de corte, cuja intensidade $(15 \mathrm{~cm})$ retirava grande parte das folhas inteiras e jovens. Em todas as cultivares, as duas primeiras medições (dia zero e dia 7 no verão e dia zero e dia 10 no inverno) foram feitas em folhas do resíduo com o mesmo critério visual. No 14으 dia (meio do ciclo de verão) e no $21^{\circ}$ (meio do ciclo de inverno), já era possível medir a fotossíntese das folhas mais jovens completamente expandidas.

Para a estimativa da taxa de fotossíntese do dossel, foi utilizado o modelo de assimilação de $\mathrm{CO}_{2}$ em folhas "de sol" e folhas "de sombra" desenvolvido por Boote \& Jones (1987), que leva em consideração o coeficiente de extinção luminosa $(\mathrm{k})$ e também a reflexão e a transmissão de luz pelo dossel. Assim, um IAF de sol é calculado analiticamente por meio do IAF total e do $\mathrm{k}$, e um IAF de sombra é calculado subtraindo-se do IAF total:

$$
\begin{gathered}
\mathrm{IAF}_{\text {sol }}=(1 / \mathrm{k})\left[1-\exp \left(-\mathrm{k} \times \mathrm{IAF}_{\text {total }}\right)\right] \\
\mathrm{IAF}_{\text {somb }}=\mathrm{IAF}_{\text {total }}-\mathrm{IAF}_{\text {sol. }} .
\end{gathered}
$$

A assimilação de $\mathrm{CO}_{2}$ pelas folhas de sol é calculada por uma curva de resposta exponencial negativa, em que a assíntota é dada pela fotossíntese máxima de folhas; a inclinação inicial, pela eficiência de utilização de luz; e a variável de entrada é a irradiância fotossinteticamente ativa absorvida $[\mathrm{k}(1-\sigma) \mathrm{PAR}]$, de acordo com a equação:

$$
\mathrm{F}_{\mathrm{sol}}=\mathrm{F}_{\max }\left\{1-\exp \left[-\mathrm{Q}_{\mathrm{e}} \times \mathrm{k}(1-\sigma) \mathrm{PAR} / \mathrm{F}_{\max }\right]\right\},
$$

em que: $F_{\max }$ é a fotossíntese de folhas individuais $\left(\mu \mathrm{g} \mathrm{m}^{-2} \mathrm{~s}^{-1}\right.$ de $\left.\mathrm{CO}_{2}\right) ; \mathrm{Q}_{\mathrm{e}}$ é a eficiência de utilização de luz $\left(\mu \mathrm{g} \mathrm{m}^{-2} \mathrm{~s}^{-1}\right.$ de $\left.\mathrm{CO}_{2} / \mathrm{J} \mathrm{m}^{-2} \mathrm{~s}^{-1}\right)$; PAR é a radiação fotossinteticamente ativa $\left(\mathrm{J} \mathrm{m}^{-2} \mathrm{~s}^{-1}\right) ; \sigma$ é o coeficiente de reflexão e transmissão. A PAR incidente para a fotossíntese de folhas sombreadas, que considera o mesmo $\mathrm{k}$ e a mesma eficiência no uso da luz refletida e transmitida por todas as folhas sombreadas, é dada pela por:

$$
\operatorname{PAR}_{\text {somb }}=\sigma \times \operatorname{PAR}\left[1-\exp \left(-\mathrm{k} \times \mathrm{IAF}_{\text {somb }}\right)\right] / \mathrm{IAF}_{\text {somb }},
$$

em que: $\mathrm{PAR}_{\text {somb }}$ é a radiação fotossinteticamente ativa para folhas de sombra. Assim, a assimilação por folhas de sombra é calculada de maneira análoga à de folhas de sol:

$$
\mathrm{F}_{\text {somb }}=\mathrm{F}_{\max }\left[1-\exp \left(-\mathrm{Q}_{\mathrm{e}} \times \mathrm{PAR}_{\text {somb }} / \mathrm{F}_{\max }\right)\right],
$$

em que: $\mathrm{F}_{\text {somb }}$ é a assimilação de $\mathrm{CO}_{2}$ por folhas de sombra. Por fim, a assimilação total do dossel é a soma de ambas as categorias de folhas:

$$
\mathrm{F}_{\text {dos }}=\mathrm{F}_{\text {sol }} \times \mathrm{IAF}_{\text {sol }}+\mathrm{F}_{\text {somb }} \times \mathrm{IAF}_{\text {somb }}
$$

em que: $\mathrm{F}_{\text {dos }}$ é a assimilação total $\mathrm{CO}_{2}$ pelo dossel.

As taxas de fotossíntese do dossel foram utilizadas para explicar as variações nas taxas de crescimento da forragem ao longo das rebrotações e entre as rebrotações de verão e inverno.

Foram utilizados os seguintes valores para as constantes: $\mathrm{PAR}=2.000 \mu \mathrm{mol}$ de fotons $\mathrm{m}^{-2} \mathrm{~s}^{-1}$ (Moreno, 2004; Pedreira \& Pedreira, 2007); $\mathrm{k}=-[\ln (\mathrm{I} / \mathrm{I} 0)] / \mathrm{IAF}$ (Brown \& Blaser, 1968), em que $\mathrm{I} / \mathrm{I}_{0}$ é a transmissão de luz no dossel, ou seja, $\mathrm{I}_{0}$ equivale a $100 \%$ da luz no topo do dossel, e I é o valor da luz que passa pelo dossel e atinge o solo, ou seja o inverso da IL. 
Assumiu-se que $\mathrm{Q}_{\mathrm{e}}$ para espécies de metabolismo C4 é de aproximadamente 0,054 , independentemente da temperatura ambiente e do regime de luz em que as plantas se desenvolvem (Dias-Filho, 2002). Assumiuse, também, valor de $20 \%$ para o coeficiente de reflexão e transmissão de luz no interior do dossel. O coeficiente de extinção de luz (k) foi calculado nos diferentes pontos do ciclo como $\mathrm{k}=-[\log$ e $(\mathrm{I} / \mathrm{Io})] / \mathrm{IAF}$, de modo que I e Io corresponderam a valores de irradiância abaixo e acima da folhagem, respectivamente. O IAF considerado para a simulação de fotossíntese de dossel foi obtido pelo método não destrutivo, com o analisador de dossel LI-COR, modelo LAI 2000.

No final de cada ciclo de rebrotação, foram feitas amostragens para a quantificação do acúmulo de forragem (AF), tendo-se retirado de cada parcela a forragem contida no interior de três molduras metálicas retangulares (área de $0,5 \times 2 \mathrm{~m}$ ) e cortado a forragem a $15 \mathrm{~cm}$ do nível do solo, com a utilização de um aparador de cerca-viva. As amostras frescas foram pesadas em campo e, a partir delas, foi tomada uma subamostra da massa homogeneizada. Para o teor de matéria seca, aproximadamente $600 \mathrm{~g}$ de massa de matéria fresca foram acondicionados em sacos de pano e levados à estufa de circulação forçada de ar a $65^{\circ} \mathrm{C}$ para secagem até peso constante. O AF de cada parcela foi calculado pela média dos três retângulos de amostragem.
Os dados foram analisados por meio do procedimento Mixed do programa estatístico SAS (SAS Institute, 2001), e a comparação de médias foi realizada por meio do comando LSMeans, a 5\% de probabilidade, pelo teste de Tukey. Para a fotossíntese de folhas individuais, as medições foram feitas em diferentes dias, de acordo com a época, a unidade experimental e o tratamento. Portanto, as medidas foram influenciadas pelo balanço hídrico, pela temperatura do ar e pela umidade relativa. A análise de variância foi feita com utilização da temperatura de folhas e a pressão de vapor d'água como covariáveis, para melhor ajuste do modelo estatístico.

\section{Resultados e Discussão}

A taxa de fotossíntese foliar não sofreu efeito da cultivar nem de estação (Tabela 1). Independentemente da estação do ano ou da cultivar de Urochloa estudada, a folha mais jovem completamente expandida possuiu a mesma capacidade de assimilação de carbono. Apesar disso, houve diferença no AF entre os ciclos de verão e inverno. Braga et al. (2008) encontraram diferentes taxas de fotossíntese para folhas em diferentes níveis de inserção, em perfilhos de Urochloa brizantha cv. Marandu, em que a folha mais jovem completamente expandida apresentou maiores taxas fotossintéticas. No mesmo trabalho, os autores registraram redução

Tabela 1. Índice de área foliar (IAF), interceptação luminosa (IL), coeficiente de extinção luminosa (k), fotossíntese foliar, fotossíntese do dossel e forragem acumulada, em dosséis de cultivares de Urochloa spp., no verão e no inverno agrostológicos ${ }^{(1)}$.

\begin{tabular}{|c|c|c|c|c|c|c|c|}
\hline Cultivar & IAF & $\begin{array}{c}\mathrm{IL} \\
-(\%)- \\
\end{array}$ & $\mathrm{k}$ & \multicolumn{2}{|c|}{$\begin{array}{l}\text { Fotossíntese foliar Fotossíntese do dossel } \\
-\end{array}$} & $\begin{array}{c}\text { Forragem acumulada } \\
\left(\mathrm{kg} \mathrm{ha}^{-1} \text { de } \mathrm{MS}\right)\end{array}$ & CV $(\%)$ \\
\hline \multicolumn{8}{|c|}{ Verão 9/1/2008 } \\
\hline Arapoty & $3,62^{\text {ns }}$ & $94,4^{\mathrm{ns}}$ & $0,80 \mathrm{ab}$ & $0,92^{\text {ns }}$ & $1,76^{\mathrm{ns}}$ & $1807,4^{\mathrm{ns}}$ & \\
\hline Capiporã & 3,67 & 94,6 & $0,79 b$ & 0,94 & 1,80 & 2280,0 & \\
\hline Basilisk & 3,73 & 94,9 & $0,82 \mathrm{ab}$ & 0,98 & 1,83 & 2236,7 & \\
\hline Marandu & 3,89 & 96,0 & $0,83 \mathrm{a}$ & 0,97 & 1,85 & 1495,7 & \\
\hline Xaraés & 3,68 & 95,1 & $0,82 \mathrm{ab}$ & 0,98 & 1,84 & 1930,3 & \\
\hline \multicolumn{8}{|c|}{ Inverno 4/9/2008 } \\
\hline Arapoty & $2,59^{\text {ns }}$ & $85,8^{\mathrm{ns}}$ & $0,75 \mathrm{ab}$ & $0,91^{\mathrm{ns}}$ & $1,57^{\mathrm{ns}}$ & $493,3^{\text {ns }}$ & \\
\hline Capiporã & 2,85 & 87,0 & $0,71 b$ & 0,92 & 1,65 & 439,7 & \\
\hline Basilisk & 2,61 & 85,8 & $0,74 \mathrm{ab}$ & 0,84 & 1,56 & 428,9 & \\
\hline Marandu & 2,49 & 84,7 & $0,75 \mathrm{ab}$ & 0,98 & 1,66 & 348,4 & \\
\hline Xaraés & 2,58 & 86,8 & $0,78 \mathrm{a}$ & 0,90 & 1,34 & 335,6 & \\
\hline \multicolumn{8}{|c|}{ Média das estações } \\
\hline Verão & $2,59 \mathrm{~A}$ & $85,8^{\text {ns }}$ & $0,75 \mathrm{~A}$ & $0,95^{\text {ns }}$ & $1,82 \mathrm{~A}$ & $1.950,0 \mathrm{~A}$ & 9,0 \\
\hline Inverno & $2,85 \mathrm{~B}$ & 87,0 & $0,71 \mathrm{~B}$ & 0,88 & $1,56 \mathrm{~B}$ & $410,0 \mathrm{~B}$ & 13,7 \\
\hline
\end{tabular}

${ }^{(1)}$ Médias seguidas de letras iguais, minúsculas dentro das estações e maiúsculas entre as estações, não diferem entre si pelo teste de Tukey, a 5\% de probabilidade. ${ }^{\text {ns }}$ ão significativo. 
no ponto de compensação luminosa, que passou de 36 para $10 \mu \mathrm{mol} \mathrm{m} \mathrm{m}^{-2} \mathrm{~s}^{-1}$ de fótons, nas folhas mais jovens em expansão, e de 3 para $1 \mu \mathrm{mol} \mathrm{m} \mathrm{m}^{-2} \mathrm{~s}^{-1}$ de $\mathrm{CO}_{2}$, nas folhas mais velhas, e constataram também a diminuição na condutância estomática e na respiração das folhas localizadas mais próximas do solo.

Segundo Braga et al. (2009), quando se deseja relacionar a produção de forragem com o processo fotossintético, outros fatores, como a partição dos fotoassimilados, devem ser cuidadosamente estudados. A assimilação bruta de carbono não se transforma necessariamente em produção colhível e tem baixa correlação com o AF $(r=0,23)$. Materiais que possuem maior taxa assimilatória podem sofrer grandes perdas respiratórias ou alocar o carbono assimilado em órgãos não colhíveis (Zelitch, 1982).

As taxas de fotossíntese do dossel, com base nos dados de fotossíntese foliar, não sofreram efeito da cultivar, mas foram distintas entre estações (Tabela 1). Não houve interação cultivar x estação, pois, durante o desenvolvimento da comunidade de plantas, com o aumento da área foliar e consequentemente da interceptação da radiação pelo dossel, ocorreu a sobreposição de folhas jovens às folhas velhas. A redução na quantidade de radiação que incide sobre as folhas mais velhas causa grande redução na sua capacidade fotossintética, levando-as à senescência. Quando se considera que a taxa de fotossíntese foliar a pleno sol corresponde à máxima taxa fotossintética de cada cultivar, podem-se relacionar esses valores com a taxa de fotossíntese de dossel, que engloba a fotossíntese de folhas na luz e na sombra, o que torna possível prever quanto o dossel ganha em eficiência de fixação de carbono com o desenvolvimento e crescimento de novas folhas.

No início da rebrotação de verão, o dossel forrageiro tinha cerca de $53 \%$ de sua fixação de carbono proveniente das folhas que estavam sombreadas no ciclo anterior. Essa proporção diminuiu com o incremento de novas folhas verdes fotossinteticamente ativas, e a fotossíntese das folhas de sombra passou a ser responsável por apenas $35 \%$ da fixação do carbono no final do ciclo de rebrotação, em que as folhas ensolaradas tiveram maior participação na assimilação de carbono. O mesmo fato ocorreu no inverno, quando a participação da fotossíntese de folhas, que estavam à sombra na fotossíntese total do dossel, passou de 66 (início da rebrotação) para 41\% (final da rebrotação). Esses resultados mostram que a proporção de folhas e a iluminação delas variaram de acordo com a forragem produzida. Dias fixos de crescimento proporcionam maior $\mathrm{AF}$ no verão e menor acúmulo no inverno, o que afetou o ambiente luminoso de crescimento das folhas. Parsons et al. (1983) observaram que, apesar de as folhas mais novas representarem apenas $42 \%$ da área foliar, foram responsáveis por $77 \%$ da fotossíntese líquida do dossel. Pedreira \& Pedreira (2007) salientaram que a produção de forragem depende mais de fatores que determinam a eficiência na interceptação da luz do que a própria eficiência fotossintética.

A taxa de fotossíntese do dossel foi maior no início da rebrotação de inverno, mesmo com o IAF mais baixo. Isto ocorreu em razão da menor sobreposição de folhas na rebrotação anterior. Essa condição permitiu que as folhas do resíduo se desenvolvessem numa condição de maior luminosidade e apresentassem maior potencial fotossintético inicial do que o resíduo das mesmas cultivares no verão. Esse padrão foi modificado com a rebrotação e, após o surgimento de novas folhas, a fotossíntese de dossel no verão superou a de inverno (Figura 1). Peri et al. (2003) observaram que, imediatamente após o pastejo ou corte, apesar do reduzido sombreamento, as folhas remanescentes apresentaram reduzida fotossíntese, provavelmente em razão de seu desenvolvimento ter ocorrido parcialmente sob intenso sombreamento.

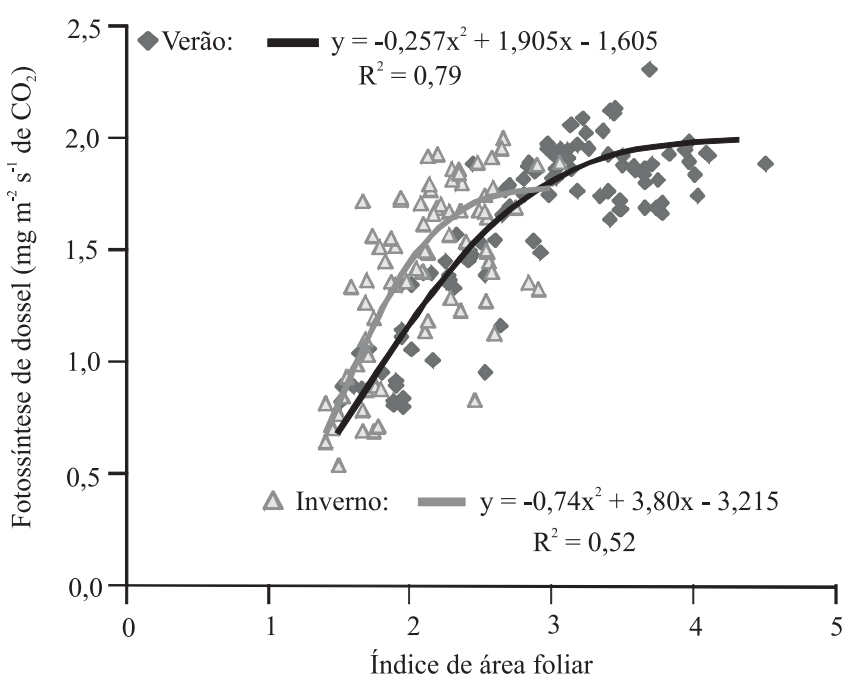

Figura 1. Variação da fotossíntese de dossel de cultivares de Urochloa spp., em função do índice de área foliar, com média de cinco cultivares em rebrotações no verão e no inverno. 
As taxas de fotossíntese foliar também apresentaram o mesmo padrão, porém as diferenças entre as estações foram mais acentuadas (Figura 2), ou seja, independentemente do IAF, a fotossíntese de folhas individuais sofreu pouca variação. Com o aumento do IAF durante a rebrotação, a maior quantidade de folhas conseguiu compensar a estabilização na taxa de fotossíntese de folhas individuais, já que a taxa de fotossíntese de dossel continuou a aumentar.

A taxa fotossintética foliar, após a completa expansão das folhas, decresce com a idade da planta, em decorrência do declínio do potencial metabólico e da mudança de posição relativa da folha dentro do dossel; como resultado, quando o IAF aumenta, o potencial fotossintético das folhas, de modo geral, diminui durante a rebrotação (King et al., 1979). De acordo com Peri et al. (2003), pastagens de Dactylis glomerata (L.) apresentam fotossíntese foliar decrescente ao longo do período de rebrotação, de modo que, aos 60 dias de rebrotação, as folhas mais novas completamente expandidas apresentam 42\% de redução na fotossíntese máxima, observada aos 20 dias. Segundo Gomide \& Gomide (2000), à medida que novas folhas e perfilhos jovens surgem em uma pastagem, é estabelecida entre elas uma competição crescente por luz, nutrientes, água, entre outros fatores de crescimento. Em decorrência do autossombreamento e do alongamento de colmos, intensifica-se o processo de senescência e morte das folhas mais velhas e até mesmo de perfilhos. Embora Brougham (1956) tenha ilustrado a importância da área foliar residual, para a rápida recuperação da pastagem, Brown et al. (1966) consideraram esta variável de pequena importância, em virtude de sua baixa eficiência fotossintética.

As taxas de fotossíntese de dossel também tiveram baixa correlação com o AF $(r=0,041)$. Essa correlação, embora significativa, mostra a baixa associação entre produção de fitomassa aérea das cultivares e seus potenciais fotossintéticos. Características do dossel, como interceptação de luz $(\mathrm{r}=0,77), \operatorname{IAF}(\mathrm{r}=0,73)$ e capacidade fotossintética das folhas $(\mathrm{r}=0,91)$ apresentaram melhor associação com a taxa fotossintética do dossel do que com o AF.

O IAF não variou entre cultivares, mas foi diferente entre estações (Tabela 1). No entanto, o coeficiente de extinção luminosa $(\mathrm{k})$ sofreu efeito tanto das cultivares quanto das estações. A cultivar Capiporã de $U$. brizantha apresentou o menor $\mathrm{k}$, possivelmente em razão de ter folhas mais eretas, com maior ângulo foliar
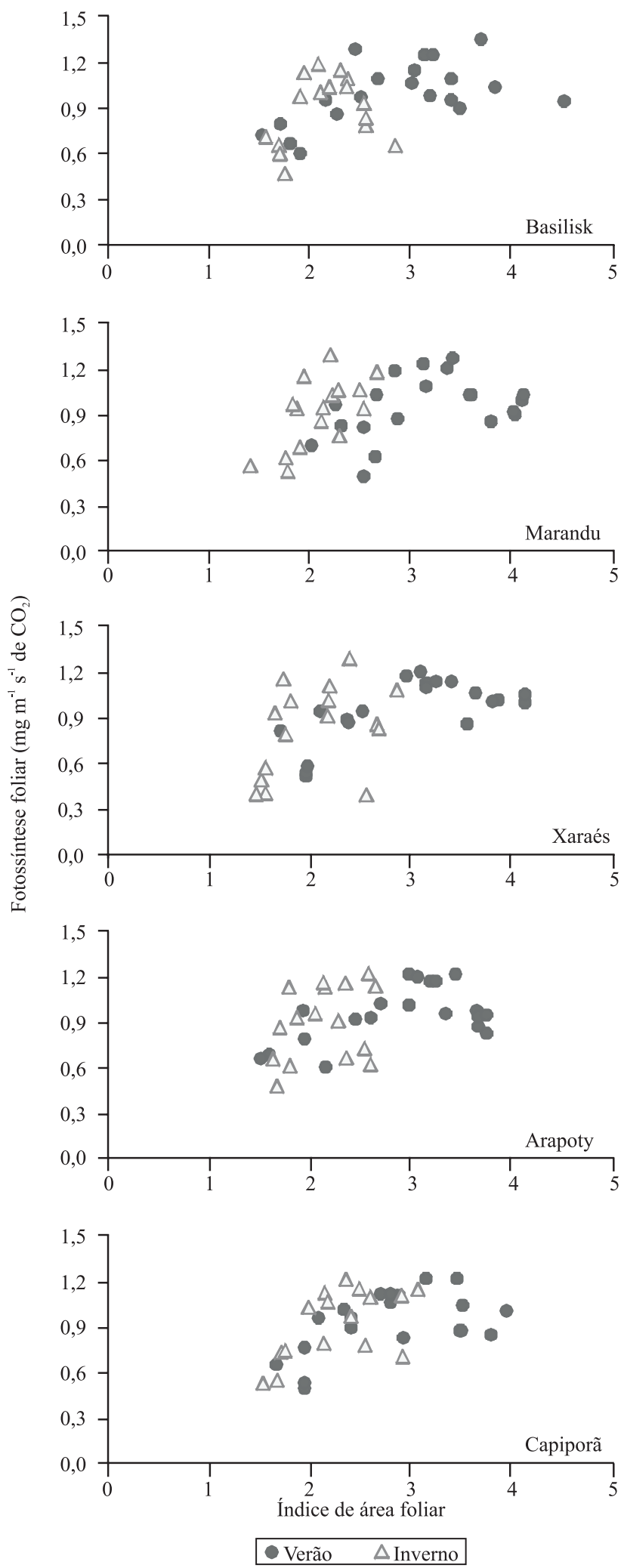

Figura 2. Variação da taxa de fotossíntese foliar, em função do índice de área foliar, em cultivares de Urochloa spp., durante rebrotações no verão e no inverno. 
em relação ao solo. A cultivar com maior valor de $\mathrm{k}$ foi a Xaraés. Segundo Fagundes et al. (2001), maiores valores de $\mathrm{k}$ podem estar associados a folhas maiores e ângulos foliares menores, ou seja, folhas dispostas mais horizontalmente no dossel. Pedreira \& Pedreira (2007) estudaram o capim-xaraés, com frequências de pastejo baseadas na interceptação da luz e em dias fixos, e encontraram respostas similares. Outra possibilidade seria a maior participação de outros componentes, como material morto que se acumula no resíduo do verão para o inverno e que interfere na interceptação de luz pelo dossel.

Pedreira et al. (2005) observaram aumento gradual na proporção de material morto com o avanço da estação seca, e Bueno (2003) encontrou maior proporção de material morto durante o outono e inverno, o que corresponde ao inverno agrostológico. As cultivares estudadas no presente trabalho não apresentaram grandes variações estruturais, o que pode ter resultado na similaridade dos resultados fotossintéticos. No entanto, Moreno (2004) que trabalhou com cinco cultivares de Panicum sob corte, encontrou variação na fotossíntese dos dosséis, evidenciada especialmente pela variação na estrutura e arquitetura do capim e seus componentes morfológicos, principalmente nos valores de IAF e k para cada cultivar. Assim, o IAF tem grande influência sobre o resultado final do modelo proposto por Boote \& Jones (1987).

\section{Conclusões}

1. Taxas de fotossíntese foliar e de dossel são fracamente associadas à produção de forragem.

2. No início de um ciclo de rebrotação no inverno, os dosséis forrageiros têm maior capacidade fotossintética do que no mesmo período no verão.

3. O índice de área foliar influencia fortemente o resultado final do modelo de simulação de fotossíntese de dossel proposto por Boote \& Jones.

\section{Agradecimentos}

À Fundação de Amparo à Pesquisa do Estado de São Paulo, por concessão de bolsa.

\section{Referências}

BOOTE, K.J.; JONES, J.W. Equations to define canopy photosynthesis from quantum efficiency, maximum leaf rate, light extinction, leaf area index, and photon flux density. In: BIGGINS, J.
(Ed.). Progress in photosynthesis research. The Hague: Martinus Niijhoff, 1987. v.4, p.415-418.

BRAGA, G.J.; MELlO, A.C.L. de; PEDREIRA, C.G.S.; MEDEIROS, H.R. de. Fotossíntese e taxa diária de produção de forragem em pastagens de capim-tanzânia sob lotação intermitente. Pesquisa Agropecuária Brasileira, v.44, p.84-91, 2009.

BRAGA, G.J.; PEDREIRA, C.G.S.; HERLING, V.R.; CERQUEIRA, P.H. de; LIMA, C.G. de. Sward structure and herbage yield of rotationally stocked pastures of 'Marandu' palisadegrass [Brachiaria brizantha (A. Rich.) Stapf.] as affected by herbage allowance. Scientia Agricola, v.63, p.121-129, 2006.

BRAGA, G.J.; PEDREIRA, C.G.S.; HERLING, V.R.; LUZ, P.H. de C.; LIMA, C.G. Herbage allowance effects on leaf photosynthesis and canopy light interception in palisade grass pastures under rotational stocking. Tropical Grasslands, v.42, p.214-223, 2008.

BROUGHAM, R.W. Effect of intensity of defoliation on regrowth of pasture. Australian Journal of Agricultural Research, v.7, p.377-387, 1956.

BROWN, R.H.; BLASER, R.E. Leaf area index in pasture growth. Herbage Abstracts, v.38, p.1-9, 1968.

BROWN, R.H.; COOPER, R.B.; BLASER, R.E. Effects of leaf age on efficiency. Crop Science, v.6, p.206-209, 1966.

BUENO, A.A. de O. Características estruturais do dossel forrageiro, valor nutritivo e produção de forragem nos pastos de capim-mombaça submetidos a regimes de lotação intermitente. 2003. 124p. Disssertação (Mestrado) - Escola Superior de Agricultura Luiz de Queiroz, Piracicaba.

DIAS-FILHO, M.B. Photosynthetic light response of the $\mathrm{C} 4$ grasses Brachiaria brizantha and B. humidicola under shade. Scientia Agricola, v.59, p.65-68, 2002.

FAGUNDES, J.L.; SILVA, S.C. da; PEDREIRA, C.G.S.; CARNEVALLI, R.A.; CARVALHO, C.A.B. de; SBRISSIA, A.F.; PINTO, L.F. de M. Índice de área foliar, coeficiente de extinção luminosa e acúmulo de forragem em pastagens de Cynodon spp. sob lotação contínua. Pesquisa Agropecuária Brasileira, v.36, p.187-195, 2001.

GOMIDE, C.A.M.; GOMIDE, J.A. Morfogênese de cultivares de Panicum maximum Jacq. Revista Brasileira de Zootecnia, v.29, p.341-348, 2000.

KING, J.; LAMB, W.I.C.; MCGREGOR, M.T. Regrowth of ryegrass swards subject to different cutting regimes and stocking densities. Grass and Forage Science, v.34, p.107-118, 1979.

LOOMIS, R.S.; WILLIAMS, W.A. Productivity and the morphology of crop stands: patterns with leaves. In: EASTIN, J.D.; HASKINS, F.A.; SULLIVAN, C.Y.; VAN BAVEL, C.H.M. (Ed.). Physiological aspects of crop yield. Madison: ASA: CSSA: SSA, 1969. p.27-47.

MORENO, L.S.B. Produção de forragem de capins do gênero Panicum e modelagem de respostas produtivas e morfofisiológicas em função de variáveis climáticas. 2004. 86p. Dissertação (Mestrado) - Escola Superior de Agricultura Luiz de Queiroz, Piracicaba. 
PARSONS, A.J.; LEAFE, E.L.; COLLET, B.; STILES, W. The physiology of grass production under grazing. I. Characteristics of leaf and canopy photosynthesis of continuously-grazed swards. Journal of Applied Ecology, v.20, p.117-126, 1983.

PEDREIRA, B.C. e; PEDREIRA, C.G.S. Fotossíntese foliar do capim-xaraés (Brachiaria brizantha (A. Rich.) Stapf. Cv. Xaraés) e modelagem da assimilação potencial de dosséis sob estratégias de pastejo rotativo. Revista Brasileira de Zootecnia, v.36, p.773-779, 2007.

PEDREIRA, C.G.S.; MELLO, A.C.L. de; OTANI, L. O processo de produção de forragem em pastagens. In: REUNIÃO ANUAL DA SOCIEDADE BRASILEIRA DE ZOOTECNIA, 38., 2001, Piracicaba. A produção animal na visão dos brasileiros: anais. Piracicaba: Sociedade Brasileira de Zootecnia, 2001. p.772-807.

PEDREIRA, C.G.S.; ROSSETO, F.A.A.; SILVA, S.C. da; NUSSIO, L.G.; MORENO, L.S.B.; LIMA, M.L.P.; LEME, P.R. Forage yield and grazing efficiency on rotationally stocked pastures of 'Tanzania-1' guineagrass and 'Guaçu' elephantgrass. Scientia Agricola, v.62, p.433-439, 2005.

PERI, P.L.; MOOT, D.J.; MCNEIL, D.L.; LUCAS, R.J. Modelling net photosynthetic rate of field-grown cocksfoot leaves to account for regrowth duration. New Zealand Journal of Agricultural Research, v.46, p.105-115, 2003.
RYMPH, S.J.; BOOTE, K.J.; IRMAK, A.; MISLEVY, P.; EVERS, G.W. Adapting the CROPGRO model to predict growth and composition of tropical grasses: developing physiological parameters. Soil and Crop Science Society of Florida Proceedings, v.63, p.37-51, 2004.

SANTOS, H.G. dos; JACOMINE, P.K.T.; ANJOS, L.H.C. dos; OLIVEIRA, V.A. de; OLIVEIRA, J.B. de; COELHO, M.R.; LUMBRERAS, J.F.; CUNHA, T.J.F. (Ed.). Sistema brasileiro de classificação de solos. 2.ed. Rio de Janeiro: Embrapa Solos, 2006. $306 \mathrm{p}$

SAS INSTITUTE. SAS/STAT user's guide. Version 7.1. Cary: SAS Institute, 2001.

THORNLEY, J.H.M. Instantaneous canopy photosynthesis: analytical expressions for sun and shade leaves based on exponential light decay down the canopy and an acclimated non-rectangular hyperbola for leaf photosynthesis. Annals of Botany, v.89. p.451-458, 2002.

WELLES, J.M.; NORMAN, J.M. Instrument for indirect measurement of canopy architecture. Agronomy Journal, v.83, p.818-825. 1991 .

ZELITCH, I. The close relationship between net photosynthesis and crop yield. BioScience, v.32, p.796-802, 1982.

Recebido em 14 de fevereiro de 2011 e aprovado em 3 de maio de 2011 